\title{
Fatal splenic rupture in Ehlers-Danlos syndrome
}

\author{
S.C. Harris, D.N. Slater and C.A. Austin
}

Royal Hallamshire Hospital, Sheffield.

\begin{abstract}
Summary: A fatal case of Ehlers-Danlos syndrome (Type IV) is described. Autopsy revealed splenic rupture that had resulted from spontaneous haemorrhage into the splenic parenchyma. This is a previously unrecorded complication of Ehlers-Danlos syndrome and should be considered in the differential diagnosis of chest and abdominal pain in patients with this condition.
\end{abstract}

\section{Introduction}

Ehlers-Danlos syndrome (EDS) is a disorder of connective tissue which can be divided into at least eight different types (Byers et al., 1982; Pope et al., 1983). Type IV EDS is characterized clinically by vascular fragility with extensive bruising. Biochemical abnormalities of type III collagen have been identified (Pope et al., 1975). Patients with this variant of EDS are susceptible to sudden death following rupture of major arteries. However, there appears to be no previous report of spontaneous intrasplenic haemorrhage and fatal rupture in a patient with EDS.

\section{Case report}

A 32 year old caucasian male was admitted with a 3 day history of left-sided chest and upper abdominal pain. There was no radiation of pain to the shoulder and no history of recent trauma.

A diagnosis of Ehlers-Danlos syndrome (Type IV) had been established in 1977. At that time his past medical history included easy bruising since childhood and operations for bilateral talipes equinovarus. The latter had been complicated by problems with postoperative haematomata. In 1976, both tibial tubercles had been transplanted for recurrent dislocation of the patellae. His brother had died aged 16 years following spontaneous rupture of the inferior vena cava. Interviews with the family yielded no relevant past medical history in the brother nor did any of the other members of his family show clinical stigmata of EDS.

S.C. Harris, M.A., M.B., B.Chir.; D.N. Slater, B.Med.Sci., M.B., Ch.B., M.R.C.P.Path.; C.A. Austin, M.A., M.B., M.R.C.P.

Correspondence: Dr S.C. Harris, Department of Pathology, Royal Hallamshire Hospital, Glossop Road, Sheffield S10 2JF.

Accepted: 3 April 1984
Physical examination, on admission, demonstrated somewhat thin skin with a prominent vascular pattern but minimal skin laxity. The scars at the sites of previous operations were papyraceous. There was a tachycardia but a normal blood pressure. There was generalized abdominal tenderness.

Investigations showed a low haemoglobin concentration $(7.4 \mathrm{~g} / \mathrm{dl})$. The peripheral blood film was normal. No abnormalities of coagulation or platelet function were found. A chest X-ray showed focal shadowing at the left base and an abdominal X-ray appeared normal.

The clinical diagnosis was considered to be spontaneous retroperitoneal haemorrhage. Whole blood transfusion was commenced but unfortunately before further treatment could be considered, his blood pressure fell rapidly and he died.

Autopsy revealed 41 of fresh blood in the peritoneal cavity. This had originated from the spleen through a $4 \mathrm{~cm}$ tear on its diaphragmatic surface. The cut surface of the spleen showed massive intrasplenic haemorrhage. The splenic artery and vein appeared normal macroscopically.

Histology showed varying degrees of organization in the haemorrhagic perisplenic tissue and a decrease in stainable collagen in the skin, aorta, inferior vena cava and splenic vessels. Splenic histology also showed a reduction of the collagen in parenchymal vessels, splenic trabeculae and in the capsule. The exact point of intrasplenic rupture was not identified.

\section{Comment}

Unfortunately collagen typing was not performed on this patient. However, the clinical history of repeated bruising, minimal skin laxity, papyraceous scars and joint hypermobility in combination with the family history, is highly suggestive of type IV EDS (also

The Fellowship of Postgraduate Medicine, 1985 
known as the ecchymotic, arterial or Sack's type). In addition, the histological appearance in the dermis and aorta are those described in this condition (Pope $e t$ al., 1975; Pope et al., 1980). Type IV EDS has been associated with a deficiency of type III collagen synthesis in some patients (Pope et al., 1975) and a defect in secretion in others (Byers et al., 1981). Type IV EDS has been divided into classical ('short-lived'), 'long-lived' and atypical varieties according to the mode of inheritance and collagen peptide patterns (Pope et al., 1980). Our case most closely conforms to the 'short-lived' autosomal recessive variety. He also exhibited two well recognized orthopaedic problems in Ehlers-Danlos patients, namely talipes equinovarus and instability of the knees (Beighton, 1970).

Sudden death in EDS is well recognised as a result of rupture of major arteries such as the aorta, popliteal or subclavian vessels (Lynch et al., 1965; McFarland \& Fuller, 1964). In addition rupture of visceral organs such as the intestine and uterus have been described (Aldridge, 1967; Rudd et al., 1983). Spontaneous

\section{References}

ALDRIDGE, R.T. (1967). Ehlers-Danlos syndrome causing intestinal perforation. British Journal of Surgery, 54, 22.

BANNERMAN, R.M., GRAF, C.J. \& UPSON, J.F. (1967). Ehlers-Danlos syndrome. British Medical Journal, 3, 558.

BEIGHTON, P. (1970). The Ehlers-Danlos Syndrome. 1st Edition p. 50, William Heinemann: London.

BYERS, P.H., BARSH, G.S. \& HOLBROOK, K.A. (1982). Molecular pathology in inherited disorders of collagen metabolism. Human Pathology, 13, 89.

BYERS, P.H., HOLBROOK, K.A., BARSH, G.S., SMITH, L.T. \& BORNSTEIN, P. (1981). Altered secretion of Type III procollagen in a form of type IV Ehlers-Danlos syndrome. Biochemical studies in cultured fibroblasts. Laboratory Investigations, 44, 336.

IMAHORI, S., BANNERMAN, P.M., GRAF, C.J. \& BRENNAN, J.C. (1969). Ehlers-Danlos syndrome with multiple arterial lesions. American Journal of Medicine, 47, 967.

LYNCH, H.T., LARSEN, A.L. WILSON, R. \& MAGNUSON, C.L. (1965). Ehlers-Danlos syndrome and 'congenital' arteriovenous fistulae. A clinicopathological study of a family. Journal of the American Medical Association, 194, 1011 . retroperitoneal haemorrhage, the clinical diagnosis in this case, has been reported by McKusick (1972).

Although death following rupture of a splenic artery $\underset{\mathbb{D}}{2}$ aneurysm has been described (Bannerman et al., 1967; Imahori et al., 1969) no direct involvement of the splenic parenchyma has been recorded to date. In view $\stackrel{9}{\stackrel{9}{+}}$ of the histological findings of reduced splenic collagen, $?$ it is perhaps surprising that this complication has not $\frac{\bar{\sigma}}{\bar{n}}$ been previously described.

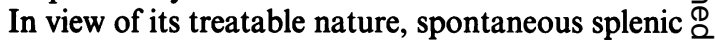
rupture should be considered in the differential diagnosis of chest and abdominal pain in patients with $\vec{\circ}$ EDS.

\section{Acknowledgements}

We would like to thank Dr J Daly for permission to report $\stackrel{-}{-}$ this case and $\mathrm{Dr} A$. Kennedy for allowing access to the autopsy report on the deceased brother. We are grateful to $\vec{\omega}$ Mrs J. Greene for her secretarial skill.

MCFARLAND, W. \& FULLER, D.E. (1964). Mortality in Ehlers-Danlos syndrome due to spontaneous rupture of $\overrightarrow{ }$ larger arteries. New England Journal of Medicine, 27@, $\overrightarrow{6}$ 1309.

McKUSICK, V.A. (1972). Heritable Disorders of Connecti Tissue. 4th edition, p. 330, C.V. Mosby: St Louis.

POPE, F.M., MARTIN, G.M., LICHTENSTEIN, J.R., PENTINNEN, R., GERSON, B., ROWE, D.W. \& MCKUSICK, V.A. (1975). Patients with Ehlers-Danlos syndrome Type IV ڤ lack Type III collagen. Proceedings of the National $\stackrel{\mathbb{Q}}{\Omega}$ Academy of Science U.S.A., 72, 1314.

POPE, F.M., NICHOLLS, A.C., DORLING, J. \& WEBB, J. (1983). 윽 Molecular abnormalities of collagen: a review. Journal of $\frac{3}{J}$ the Royal Society of Medicine, 76, 1050.

POPE, F.M., NICHOLLS, A.C., JONES, P.M., WELLS, R.S. \& LAWRENCE, D. (1980). EDS IV (acrogeria): new 윽 autosomal dominant and recessive types. Journal of the Royal Society of Medicine, 73, 180.

RUDD, N.L., NIMROD, C., HOLBROOK, K.A. \& BYERS, P.H. (1983). Pregnancy complications in Type IV EDS. Lancet, ᄋ i, 50 . 